\title{
Centenario del nacimiento del Dr. D. Antonio Puigvert Gorro
}

\author{
M. Pérez Albacete \\ Coordinador de la Oficina de Historia
}

Actas Urol Esp 2005; 29 (9): 807-814

$\mathrm{E}^{1}$ 20 de enero de 1967, en el anfiteatro de la antigua Facultad de San Carlos de Madrid, el Dr. Puigvert impartió una conferencia para celebrar sus bodas de oro como miembro de la Asociación Española de Urología y el entonces presidente, Dr. Martínez Piñero, resaltó su labor ininterrumpida en pro de la Asociación, de la Urología española y de la mundial. Con el acto de hoy la Asociación, por medio de su Oficina de Historia, desea rendir un homenaje a su memoria, queremos honrar a una de las principales personalidades de la Urología española, en el año en el que se cumple el centenario de su nacimiento (Fig. 1).

Es imposible, en el breve espacio de tiempo del que disponemos, glosar todo lo que representa su persona; de fuerte carácter, de gran inteligencia, de fino ingenio y de imaginación creativa, fue un polemista agudo y un sagaz observador, con una tremenda capacidad de trabajo y exigente en el buen hacer; poseía una profunda e inquisitiva mirada que mantenía fija en su interlocutor y que a veces, llegaba a producir desasosiego; pero, por otra parte, era atento y se preocupaba por sus enfermos (Fig. 2), a quienes dedicaba lo mejor de sí mimo; todo esto le hizo ser respetado, y temido en ocasiones, pero siempre admirado por su alta calidad científica y por su gran humanidad por todos aquellos que lo trataron y por todos aquellos que recibieron su magisterio.

Nace el 26 de abril de 1905 en la, por entonces, pequeña localidad agrícola de Santa Coloma de Gramanet, población cercana a Barcelona y en donde su padre, al que define como "médico austero y ejemplar", ejercía en el medio rural; cuando contaba pocos meses, la familia se trasladó al municipio de San Andrés de Palomar, barriada obrera próxima a la Ciudad Condal, en la que transcurrió su infancia; comenzó allí los estudios primarios, en el

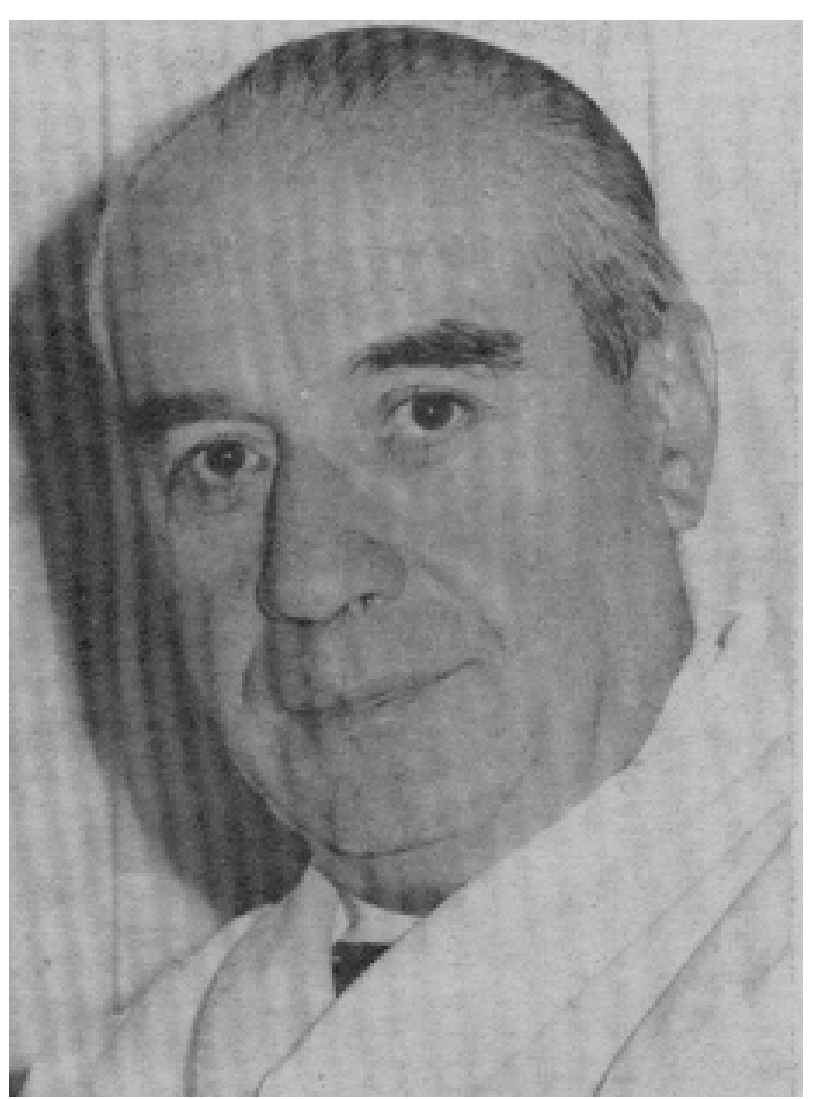

FIGURA 1. Dr. Puigvert.

Ateneo Obrero, y realizó los de bachillerato, que inició a los diez años y finalizó con 16, en el Instituto General y Técnico de Barcelona; siguió el ejemplo paterno, se matriculó en la Facultad de Medicina y, buen estudiante, obtuvo la licenciatura con 23 años; fue alumno interno y preparador anatómico, por oposición, con el catedrático de Anatomía Dr. D. Manuel Serés Ibars (1877-1928); en las salas de disección transcurría la mayor parte de su tiempo en acondicionar las piezas para la clase del día siguiente, llegó a trabajar sobre unos mil cadáveres, lo que le proporcionó una sólida base para el posterior desarrollo de su carrera como cirujano; tras un nuevo concurso, prosiguió como interno de ciru- 


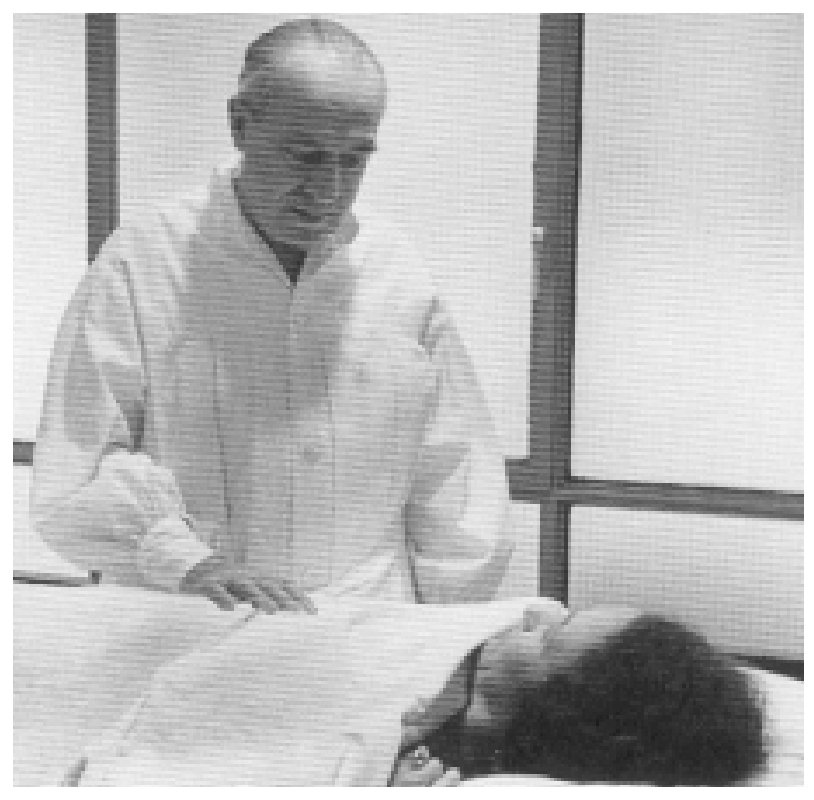

FIGURA 2. El Dr. Puigvert atiende a una enferma.

gía, junto al Dr. Serés, profesor responsable de la docencia urológica, quien lo tomó como practicante por las tardes en su clínica privada en donde comenzó a limpiar sondas, a hervir aguas, a preparar jeringas y pronto pasó a lavar vejigas; más adelante, con 21 años, la visión cistoscópica de un papiloma vesical pediculado que describe como "soberbio espectáculo, sugestiva imagen de un alga marina en el fondo del mar", quedó grabada en su retina de estudiante y fue el determinante para que se decidiera por la especialización urológica. Su primera intervención quirúrgica fue una talla hipogástrica, la realizó antes de finalizar la carrera, a petición del médico responsable de la guardia del hospital, que era pediatra, a un enfermo en retención aguda de orina; conocedor de la técnica, llevó a cabo la operación sin temor y sin dificultad y el paciente tuvo una buena evolución lo que hizo que, a partir de entonces, efectuase alguna otra en circunstancias excepcionales; continuó trabajando en la clínica privada del Dr. Serés en la atención médica primero para pasar, posteriormente, a ser su ayudante en el quirófano. Una vez finalizada la carrera, en 1928, comenzó realmente su práctica quirúrgica y, tras el fallecimiento en el mes de abril del mismo año del que siempre consideró como su mentor y maestro, se hizo cargo de su clínica a la que acudían las principales personalidades catalanas.
Marchó a Berna, en Suiza, con la ayuda de un paciente agradecido, donde trabajó como asistente del Dr. Wildbolz en el Inselspital de dicha ciudad, luego a París donde, para ampliar sus conocimientos urológicos, estuvo en el Hospital Necker con el profesor Felix Legueu y en el Lariboisière con el Dr. George Marion. Regresa a Barcelona y en 1932 monta su clínica privada, ubicada en el número 345 de la calle Provenza; al siguiente año obtiene por oposición una plaza de médico auxiliar en el servicio de Urología del Hospital de la Santa Cruz y de San Pablo de Barcelona.

Inicia ya su obra escrita que queda reflejada en centenares de comunicaciones y de trabajos urológicos publicados, además de en ensayos y en libros diversos pero, sobre todo, en varios tratados de gran trascendencia por su importancia y oportunidad en el momento de su aparición, el primero fue el Atlas de Urografía, editado en 1933.

Desde el final de sus estudios había aprendido a interpretar las placas radiográficas de la exploración del aparato urinario de la mano del Dr. Carrasco Formiguera y en la obra, de 215 páginas, recoge 264 láminas radiológicas que desde 1928 había recopilado en su sanatorio aunque indica que es preciso dominar la semiología clínica ya que la radiología complementa pero no sustituye el conocimiento de la enfermedad, por ello en el libro presenta a la vez el estudio anatomo clínico y el radiológico en las diferentes afecciones urológicas, además de una completa visión de todos los datos que la radiografía puede ofrecer al especialista; expone únicamente su propia casuística y rehuye las citas bibliográficas, pero se prepara concienzudamente para la redacción de la obra y reseña 760 trabajos consultados; en 1944 amplía el estudio con la edición del Tratado de Urografía Clínica. Con los años el "atlas» se convirtió en un clásico de la Urología española y, agotado tiempo atrás, ante las insistentes peticiones realizó una completa renovación del mismo, aumentó considerablemente su contenido con una extensa iconografía y añadió láminas dibujadas en acuarela por el Sr. D. Rafael Alemany; vio la luz en 1982 y tuvo una reedición en 1989. 
En 1935 aparece el segundo, una breve monografia sobre Tuberculosis renal que, en 1941, rehace con el título de La tuberculosis genitourinaria, ambas escritas según los cánones de la época preantibiótica y en las que presenta la concepción clásica de la enfermedad; en 1958 ofrece una nueva versión completamente renovada, $L a$ tuberculosis urinaria y genital masculina, en la que expone, a lo largo de 398 páginas, el concepto etiopatogénico y el terapéutico ya con los modernos tratamientos tuberculostáticos y describe su experiencia en la nefrectomía parcial en esta enfermedad, incluye también una excelente iconografía radiológica de piezas operatorias y de necropsias recogidas todas ellas de su archivo de más de 25.000 historias clínicas acumuladas en los 25 años de existencia del Instituto de Urología en aquellas fechas.

Su tercera obra, Endoscopia urinaria, aparece en plena Guerra Civil, en 1939, y con ella marca un hito en la bibliografía médica española al escribir un libro totalmente original, con el que quería demostrar que no era preciso recurrir a la traducción de textos extranjeros para disponer en nuestra literatura de uno que reuniera todos los conocimientos relativos a la exploración cistoscópica del aparato urinario; fue galardonada con el "Premio Rubio" por la Real Academia Nacional de Medicina, en 1942; en ella, y a lo largo de 228 páginas, muestra toda la patología urológica que precisa de la exploración cistoscópica, del cateterismo ureteral, así como de la biopsia y de la litotricia vesical, además de los medios y el modo de realizarlos; la acompaña de un millar de citas bibliográficas lo que nos indica la extraordinaria preparación y el gran estudio que su redacción llevó, está adornada toda ella con 260 imágenes endoscópicas, recogidas en 52 láminas y extraídas de su propio archivo. La trascendencia que tuvo nos la da su rápida desaparición, agotada la edición y considerada como un clásico muy apreciado, realizó una reedición con puesta al día y totalmente renovada en 1969, a la que siguió otra en 1975 y una cuarta en 1983 dada la insistente demanda de la misma.

Al comienzo de la Guerra Civil, en 1936, recibió la propuesta de un senador colombiano, paciente suyo, el Sr. Grillo Caramillo, de hacerse cargo de la jefatura del Servicio de Urología en un nuevo hospital erigido en Bogotá, ofrecimiento que declinó por mantener su clínica barcelonesa en la que, ya en aquella época, tenía recogido un importante número de historias clínicas junto a radiografías, resultados de exploraciones y de laboratorio y su ya considerable biblioteca; en 1938, con el avance de la guerra, se ve obligado a alistarse, es destinado como capitán médico al Hospital de Vallcarca en el que asistió al jefe del Estado Mayor republicano conocido como El Campesino y, al finalizar la contienda, permaneció en un hospital de campaña para presos de guerra.

En 1941 se reintegró a la vida civil y a su actividad urológica como médico en el Hospital de San Pablo; en el mismo año, en Madrid, obtiene el grado de doctor con su tesis Exploración radiográfica de los órganos urinarios durante el acto quirúrgico, se presenta también al concurso convocado para cubrir la plaza de jefe de servicio de Urología en el Hospital de San Pablo, vacante tras el fallecimiento del Dr. Mestre Morer (1870-1938), pero, al necesitar un certificado de depuración política, que obtuvo pasado el plazo reglamentario, no la consigue y fue ganada por su compañero el Dr. D. Vicente Compañ (1881-1976) por lo que tuvo que esperar hasta su jubilación, en 1951, para, en un nuevo concurso oposición, lograrla.

En 1944, en plena II Guerra Mundial, inicia su primera gira por Hispanoamérica, odisea de veintidós días de viaje, que describe espléndidamente en Un viaje en Clipper; para llegar a Buenos Aires, establece estrechas relaciones con los urólogos de varios países, en 1944 en Panamá y en Río de Janeiro imparte sendas conferencias sobre "nefrectomía parcial». En junio de 1947 dicta un curso de Urología de postgrado en el Hospital de Santo Tomás en la República de Panamá, completado con sesiones operatorias y endoscópicas, además de efectuar una prostatectomía perineal en el Hospital de la zona norteamericana del Canal e intervenir por una hiperplasia prostática al Presidente de la República, Omar Torrijos, con excelente resultado. En el año 1950 desarrolla, en la Facultad de Medicina de la Universidad de Córdoba, Argentina, un curso de perfeccionamiento urológico con conferencias y sesiones operatorias; al constituirse la Confede- 
ración Americana de Urología, por el Dr. D. Álvaro Cumplido de Sant' Ana en 1970, fue nombrado representante español en la misma al siguiente, $\mathrm{y}$ así prosigue, año tras año, acudiendo no sólo a Sudamérica en donde trata a los principales líderes, entre ellos a Juan Domingo Perón, de Argentina, con quien le unió una buena amistad y lo tuvo por consejero, Joao Gulard, de Brasil, Alberto Trujillo, de la República Dominicana, quien le propuso crear un Instituto de Urología en Santo Domingo, sino también a EE UU y a diversos países de Europa y del norte de África donde divulga su experiencia, se relaciona con los principales urólogos, conoce otros centros e intercambia conocimientos.

En 1943 modifica su clínica para crear el Instituto de Urología (Fig. 3), con el propósito de aprovechar al máximo todos los medios disponibles tanto para la función asistencial como para la docente y en el que recoge todo el historial médico que celosamente guarda desde la finalización de su carrera en 1928 (son ya cientos de historias clínicas, de radiografías, de preparaciones anatomopatológicas y de datos analíticos y cinematográficos de operaciones quirúrgicas); cuenta el centro con seis consultorios y treinta y ocho camas de hospitalización, parte de ellas dedicadas a la atención de pacientes con escasas posibilidades económicas, con un departamento radiológico dotado de un moderno aparato y una sala de endoscopia, con una buena colección de instrumental, con un laboratorio que lleva anexa una zona especial para el análisis anatomo patológico, con un amplio quirófano con anfiteatro para seguir el curso de las operaciones y con una biblioteca sala de estudio además de cinemateca,

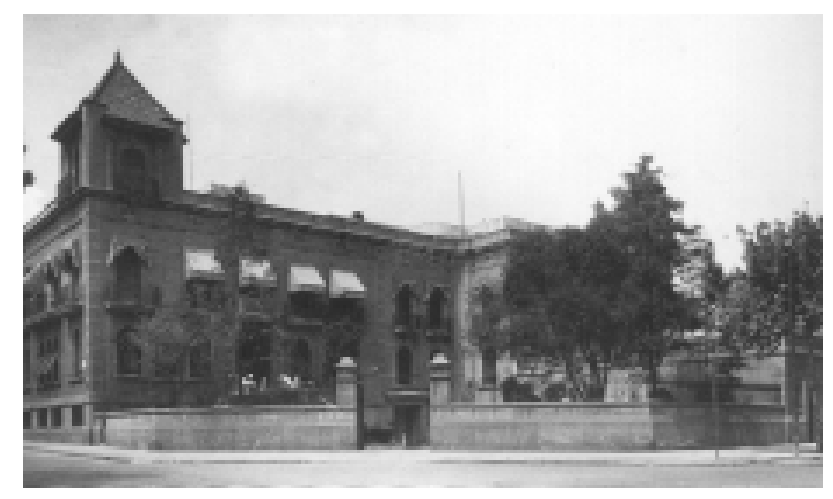

FIGURA 3. Primitivo Instituto de Urologia. en donde se llevan a cabo sesiones clínicas desde sus inicios; en la discusión y en la toma de decisiones clínico terapéuticas y quirúrgicas participan todos los miembros del equipo médico, bajo el estricto control del Dr. Puigvert, cabeza de un centro en progresivo aumento en el que se integra un nutrido grupo de excelentes profesionales, que trabajan con plena dedicación y que le dan la categoría que su fundador intuía.

La resolución de aportar al Hospital de la Santa Cruz y de San Pablo (Fig. 4) todo el material científico que posee rondaba por su cabeza desde el año $1944 \mathrm{y}$, con ocasión de su viaje a América, dicta las disposiciones testamentarias oportunas para que todo el instrumental quirúrgico, clínico, científico y bibliográfico pasase a engrosar el servicio de Urología de dicho hospital. La idea de unir su clínica a la hospitalaria con la finalidad de acoger en un solo centro toda la actividad médica, la pública y la privada, "al igual que para la templanza del alma, los templos son iguales para las distintas condiciones sociales, para sanar el cuerpo los centros deben ser los mismos, atendiendo por igual a todas las clases sociales y económicas", data de 1951 año en que, tras su incorporación como jefe de servicio al centro, vislumbra esta posibilidad y la expone ante los componentes de la Muy Ilustre Administración del Hospital quienes, después de estudiar, analizar y discutir el proyecto aceptan dicha anexión y, así, en 1954 ve plasmado su sueño y traslada su Instituto al nosocomio, acompañado de las miles de historias clínicas acumuladas en su clínica y que constituye ya una de las colecciones urológicas más importantes del mundo, además de un completo fichero bibliográfico con 70.000 fichas de trabajos y un gran número de libros sobre urología de su propiedad; para poder

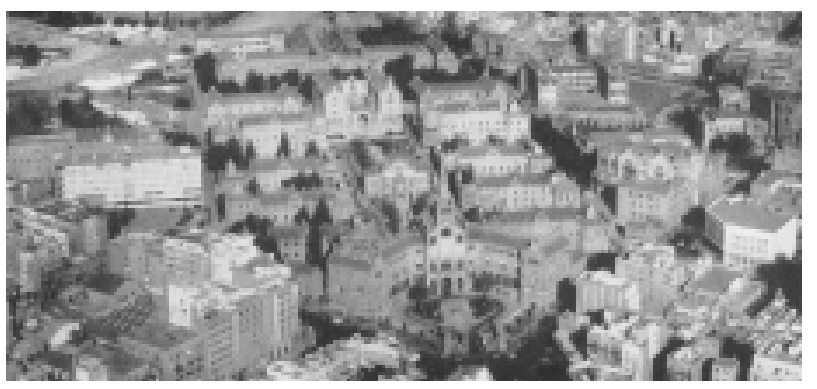

FIGURA 4. Panorámica del Hospital de San Pablo. A la izquierda edificio moderno, sede de la Fundación Puigvert. 
dar cabida a tan ingente cantidad de elementos precisa ampliar el pabellón de la Asunción (Fig. 5), donde se encontraba ubicado el servicio de Urología, que, a partir de esa fecha, se denomina Instituto de Urología del Hospital de la Santa Cruz y de San Pablo.

La preocupación sobre el destino de tanto material científico, así como, el de sus múltiples colaboradores y trabajadores del Instituto influyó poderosamente en la creación de la Fundación Puigvert para que, al faltar él, prosiguiera la actividad en el centro y, de este modo, se diera continuidad a su obra: la idea fue bien acogida por los miembros de la M. I. Administración del Hospital que permiten que se construya un recinto en los terrenos del nosocomio y el 12 de abril de 1961 se constituye ante notario la Fundación Puigvert, aprobada por O. M. de 20 de julio de 1961 (BOE número 188, de 8 de agosto de 1961), cuyo principal objetivo médico benéfico es el de incrementar las actividades del Instituto de Urología en el Hospital, "poner al alcance de la población de cualquier nivel socio económico los mismos medios humanos y técnicos", y sus fines, la asistencia, la docencia y la investigación. En 1966, se termina la ampliación y es inaugurado por el general Franco el nuevo centro privado, que cuenta con sesenta y cinco camas y diez consultorios, que hay que sumar a las setenta y

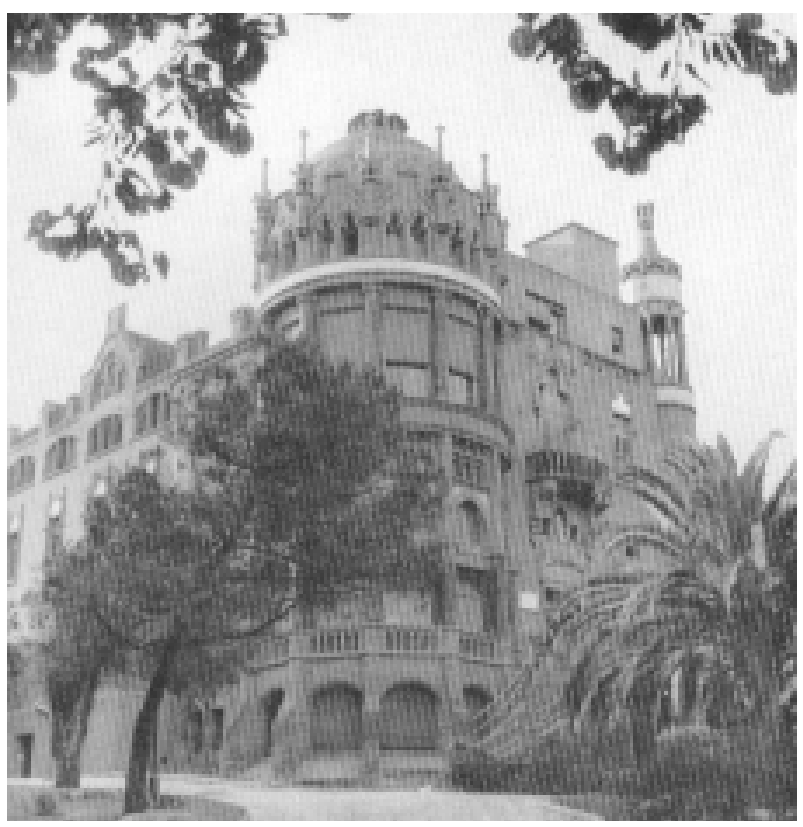

FIGURA 5. Pabellón de la Asunción. cinco camas y ocho consultas públicas de las que ya dispone el servicio. Culmina con ello su obra magna, con la que logró uno de los principales centros urológicos europeos con labor asistencial, docente e investigadora así como una sede de importantes cursos internacionales de Urología, Andrología y Nefrología, que también trasladó, en 1967, a los países de habla española en Sudamérica.

Desde la creación del Instituto asisten a él médicos para especializarse en Urología y, ya en 1946, se imparten en el centro cursos de formación de postgrado, el primero de todos fue en abril de dicho año, "Ocho lecciones sobre fisiopatología renal", desarrollado por el Dr. Oriol, jefe de la sección experimental del centro; en abril de 1947 se celebra el segundo, sobre "Endoscopia vesical», en mayo de 1948 tiene lugar el tercer curso monográfico, de ocho días de duración, con lecciones teóricas y demostraciones iconográficas, el cuarto, "Ocho lecciones sobre tuberculosis urinaria", en abril de 1949 y así se han venido sucediendo año tras año, cada vez con mayor aceptación por todos los urólogos españoles e hispanoamericanos.

En 1947 se convocan las primeras plazas de médico interno en el Instituto, a plena dedicación y consideradas como becas de un año prorrogable hasta tres, para la formación en Urología; en 1952 el Dr. fue pionero al instituir el primer programa teórico-práctico de rotación de médicos por todas las secciones de la especialidad, con objeto de dotarlos de la experiencia y de los métodos diagnósticos y terapéuticos precisos para su ejercicio; por su plan de trabajo y estudios el centro fue reconocido oficialmente por Orden Ministerial de 26 de julio de 1967 (BOE de 30 de agosto) como Escuela de Especialización de postgrado en Urología (Fig. 6), dependiente de la Universidad Autónoma de Barcelona, bajo la dirección del Dr. Puigvert.

La visión de futuro del doctor (como quería que se le llamase) le hace prever las necesidades asistenciales que el progresivo incremento de la atención urológica va a precisar, por lo que se preocupa de disponer de personal con preparación específica en cada una de las ramas de la especialidad, de ahí que se encargase de organizar en el Instituto el departamento de endoscopia urinaria al Dr. D. Ignacio Ponce de León a quien, 


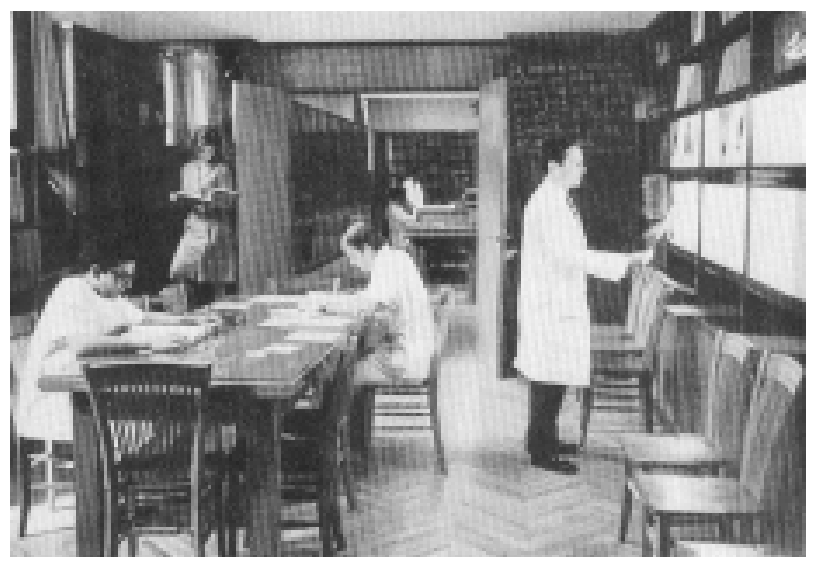

FIGURA 6. Médicos residentes en la Biblioteca de la Fundación.

posteriormente, hace responsable del desarrollo de la exploración urodinámica y quien, con su dedicación al frente de este departamento, se convirtió en la primera figura nacional en este campo; del mismo modo, ya en 1954 auguró también la importancia que adquiriría el estudio andrológico del varón, por lo que estimuló la puesta en marcha de una unidad de esterilidad masculina y encomendó al Dr. D. José María Pomerol Serra (19202004) su planificación y dirección; en 1958 fue elevada a la categoría de servicio de Andrología, uno de los primeros del mundo en esa disciplina y, gracias a la labor realizada por el Dr. Pomerol, se constituyó el Comité Internacional de Andrología (CIDA) en 1970 (Fig. 7), presidido por el profesor Manzini, de Buenos Aires, cuyo primer congreso se celebró en 1976, en la Fundación, y que, tras posteriores transformaciones, dio lugar a la creación de la Sociedad Internacional de Andrología.

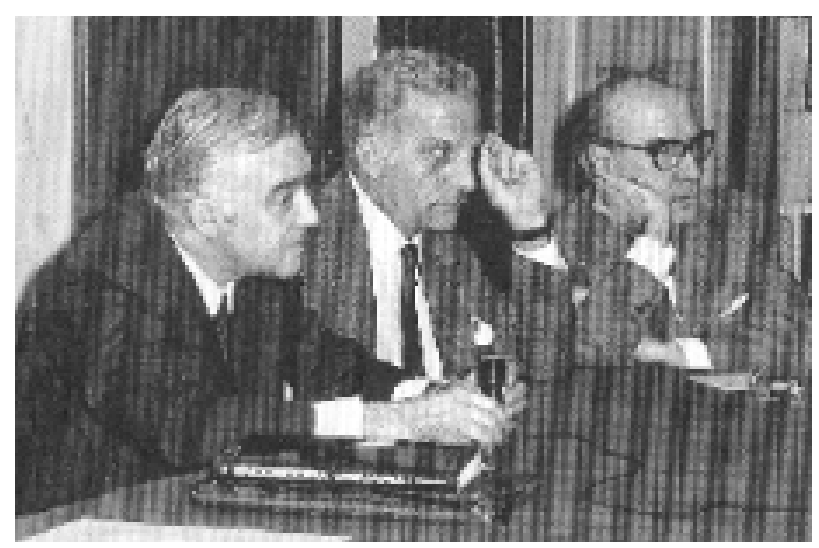

FIGURA 7. Comité Internacional de Andrologia (CIDA). Drs. Pomerol, Manzini y Puiguert.
En 1964 introdujo la unidad de nefrología al frente de la cual colocó al Dr. D. Gerardo del Río Pérez, con lo que fundó el primer servicio de nefrología en España. Potenció la cine-radiografía como medio diagnóstico funcional y la cinematografía aplicada al perfeccionamiento quirúrgico, así como la dedicación exclusiva de un patólogo al estudio de las piezas del aparato génito urinario. Con la creación de todas estas unidades se comienza a denominar el Centro como Instituto de Urología, Nefrología y Andrología, (IUNA).

Cofundador de Archivos Españoles de Urología en 1944, junto a los Drs. Enrique Pérez Castro (1908-1980) y Luis Cifuentes Delatte (19072005), inicia, en 1954, la edición de las Series del Instituto de Urología, en las que se recogen separatas de todos los trabajos publicados anualmente por el cuerpo médico de la institución y que proseguirá apareciendo hasta el número 23 , en el año 1970, en que dará paso a la creación de la revista Anales de la Fundación Puigvert que, en 1982, por cuestiones legales, cambia el nombre por el de Actas de la Fundación Puigvert, que persiste hasta nuestros días.

Como investigador, describió la hipoplasia medular renal, a la que denomina megacaliosis, que estudia en 1965 en su obra Malformaciones de la pirámide renal de Malpighi, en edición bilingüe español-francés, fruto del análisis y revisión de su extensa y rica iconografía, en ella se sistematizan y organizan las malformaciones congénitas renales de origen Wolfiano, de las que aclara su etiopatogenia; completa este trabajo en 1981 con la aparición de Semiología medular del riñón, estudio clínico y radiológico. Colaboradores y amigos lo animan a que recoja en un libro su labor quirúrgica de tantos años (Fig. 8), a que describa sus métodos operatorios, técnicas inéditas unas, modificadas o enriquecidas con detalles propios otras, y así, en 1971, aparece su esperado Tratado de Operatoria Urológica en el que muestra varias operaciones que llevan su nombre, además de instrumental quirúrgico, catéteres y sondas diversas diseñadas por él; se encuentra adornada la obra con una selección de las magníficas láminas y esquemas que, desde 1945, el dibujante Sr. D. Antonio Belenguer recoge en sus sesiones operatorias y que, a lo largo de los años, constituyen una serie de más de 5.000 bocetos. 


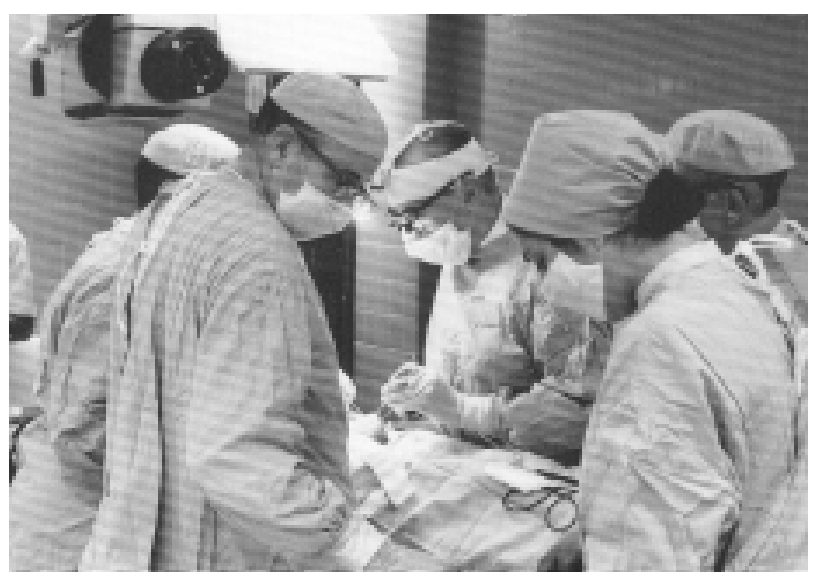

FIGURA 8. Dr. Puigvert en el quirófano.

Su inquietud científica le hace profundizar en el conocimiento evolutivo de la patología objeto de estudio, efectuar una amplia revisión bibliográfica e investigar la obra de los que se dedicaron a ella, de forma que obtiene el desarrollo histórico del proceso; todas sus obras aparecerán, pues, precedidas, y enriquecidas por tanto, por una extensa y espléndida introducción histórica; como ejemplo, su magnífico análisis sobre el desarrollo de los "Fungus vesicales", inicio de su discurso de ingreso en la Real Academia de Ciencias de Barcelona en 1952, Tumores de la vejiga. Evolución y fundamentos de clasificación anatomo-clínica. Destacamos, por la trascendencia lograda, los trabajos sobre el Tratado de todas las enfermedades de riñón, vejiga y carnosidades de la verga y orina, de Francisco Díaz (editado en 1588) y que, tras su publicación en inglés, logran que la obra de Díaz sea considerada mundialmente como el "primer tratado de Urología del mundo" y que su autor sea reconocido como "padre de la Urología"; a su vez crea, en 1972, la "Medalla Francisco Díaz", otorgada a la personalidad que más haya destacado por su contribución y dedicación a la especialidad y que entrega la Asociación Española de Urología cada año; encontramos, también, su excelente $\mathrm{El}$ mal de Piedra del riñón, de 1897, en el que pormenoriza la evolución de la litiasis a través de los tiempos. Subrayamos su papel como bibliófilo recopilador de obras urológicas antiguas además de señalar su interés en efectuar reproducciones facsímil de las mismas, como la que realizó, en 1968, de la ya citada de Francisco Díaz. Por último, resaltamos el que sistemáticamente publicase una glosa de cada compañero fallecido.
En 1953 es también nombrado director del servicio de Urología de Hospital de Tarrasa y en 1956 jefe de equipo quirúrgico de Urología en la Residencia de la Seguridad Social, Francisco Franco, de Barcelona. En 1963 se acredita, mediante concurso, como profesor de Urología en el Hospital de la Santa Cruz y de San Pablo y en 1971 fue designado catedrático de Urología en la Universidad Autónoma de Barcelona en virtud de los grandes méritos desarrollados a lo largo de su vida en la especialidad (Fig. 9). En 1976 ingresa en la Sociedad Española de Médicos Escritores con la conferencia titulada, Del Saber y del Hacer Urológico.

Fue distinguido como miembro honorario de la Universidad Nacional Argentina y de las de Brasil, Chile, California e Israel, doctor Honoris Causa de diversas Universidades nacionales y extranjeras y condecorado en reconocimiento de su labor científica y pedagógica con la Gran Cruz de la Orden de Alfonso X el Sabio, la Encomienda de la Orden de Isabel la Católica, la Medalla de Oro al Mérito del Trabajo y la Medalla de Oro de Barcelona, con la Cruz de San Jorge de la Generalidad de Cataluña, la Cruz de Caballero de la Legión de Honor francesa y la de Oficial de la Orden do Cruceiro brasileña; perteneció a numerosas sociedades científicas, fue académico de la Real de Ciencias Médicas de Barcelona, de la de Zaragoza y de la de Bilbao, miembro de la Académie de Chirúgie de París, de la Sociedad Internacional de Urologia, de la Española, de la Francesa y de otras varias, recibió además distinciones, condecoraciones, homenajes y reconocimientos múltiples que sería tedioso incluir.

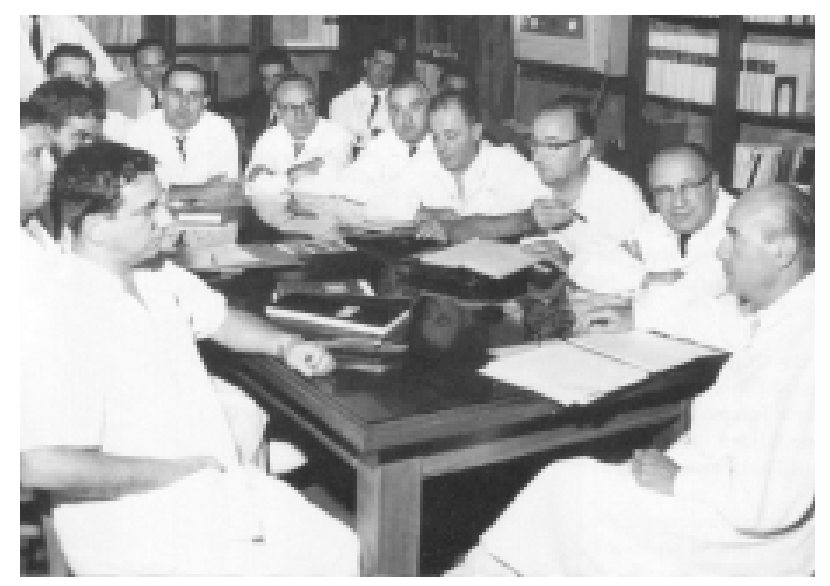

FIGURA 9. Sesión clinica en la Fundación Puigvert. 
Prosiguió al frente de la Institución hasta su retiro por edad y aún así continuó asistiendo regularmente al centro hasta que su capacidad vital se lo impidió. Falleció en el seno de su Fundación, en su querida Barcelona, a los 84 años, el 17 de mayo de 1990, fecha que recuerdan en el centro cada año con la celebración de un Memorial en honor de quien, según mi criterio personal, ha sido la personalidad de mayor trascendencia y que mayor huella ha dejado en la Urología española tras la insigne figura del médico del siglo XVI.

\section{REFERENCIAS}

- Atlas de Urografia, (1933): 215 págs., Salvat edit. Barcelona.

- Endoscopia urinaria, (1939): 228 págs., 1 ${ }^{a}$ edic. Salvat edit. Barcelona-Buenos Aires.

- Tuberculosis génitourinaria, (1941): 160 págs., Salvat edit. Barcelona-Buenos Aires.

- Tratado de urografía clínica, (1944): Salvat edit. BarcelonaBuenos Aires.

- Un viaje en Clipper, (1945): 50 págs., Barcelona.

- Tumores de la vejiga. Evolución y fundamentos de clasificación anatomo clínica, (1952): 60 págs., discurso de ingreso en la Real Academia de Medicina de Barcelona, Barcelona.

- Tuberculosis urinaria y genital masculina, (1958): 375 págs., Salvat edit. Barcelona-Madrid-Buenos Aires.

- Endoscopia urinaria, (1962): 2ª ed. 215 págs., edit. Eco S. A., Barcelona.

- Malformaciones de la pirámide renal de Malpighi, (1965): 202 págs., edic. Bilingüe español francés, edit. Eco S A., Barcelona.

- Tratado de operatoria urológica, (1971): 525 págs., edit. Labor S. A., Barcelona.

- Del saber y del hacer urológico, (1976): conferencia de ingreso en la sociedad de médicos escritores, edit. Eco S.A., Madrid.
- Semiología medular del riñón. Estudio clínico y radiográfico, (1981): 185 págs., edit. JIMS, Barcelona.

- Mi vida y otras más, (1982): 282 págs., edit. Planeta, Barcelona.

- El mal de piedra del riñón, (1985): 150 págs., edit. Salvat, Barcelona.

- Atlas de Urografía , (1986), reedición (1989): 566 págs., 2 $2^{\text {a }}$ edición, edit. Salvat, Barcelona.

- Díaz Rubio M. 100 Médicos españoles del siglo XX. 200; pág. 156, impr., Gráficas Marte, Madrid.

- Gausa Gascón J, Vicente Rodríguez J. Recordando la figura del Dr. Puigvert y su obra, Urol Integr Invest 2002;7(2):199204.

- Gausa Rull P. Pequeña historia sobre la evolución de la Urología en Barcelona, I Congreso Internacional de Historia de la Medicina Catalana, II: 312, 1971; Barcelona.

- Insausti Cordón JL. Compendio histórico de la Urología Española y de su Asociación, pág. 66 y 130, IV Congreso Iberoamericano de Urología, 1982; Acapulco (Méjico), Reycosa, Madrid.

- Pérez Albacete M. 100 Figuras de la Urología Española, 2005; pág. 180, tipograf. San Francisco, Murcia.

- Rouseaud Barón A, Ponce de León Roca J, Gausa Gascón K, Serrallach Orejas M. El Dr. Antonio Puigvert y su obra en Historia Biográfica y Bibliográfica de la Urología Española, 2002; pág. 185-193, Edicomplet, Madrid.

- Solé Balcels FJ, Antonio Puigvert. El choque de pareceres. Un avance en el conocimiento, Arch Esp Uro 1991;44(4):333.

- Vela Navarrete R. Cirugía reconstructiva pieloureteral en la obra de Antonio Puigvert. Arch Esp Uro 1991;44(4):343-349.

- Villavicencio Mavrich H. La estela de la Urología de Antonio Puigvert, Arch Esp Uro 1991;44(4):337.

Dr. M. Pérez Albacete

Servicio de Urología. Hospital Virgen de la Arrixaca Ctra. Murcia-Cartagena, s/n

30120 El Palmar (Murcia)

e-mail:mariano.perez2@carm.es

(Trabajo recibido el 23 de junio 2005) 